\title{
Evaluation of Focal Hepatic Masses: A Comparative Study of MRI and CT
}

\author{
Gary M. Glazer, ${ }^{1}$ Alex M. Aisen, ${ }^{1}$ Isaac R. Francis, ${ }^{1}$ Barry H. Gross, ${ }^{1}$ \\ John W. Gyves, ${ }^{2}$ and William D. Ensminger ${ }^{2}$ \\ Departments of ${ }^{1}$ Radiology and ${ }^{2}$ Internal Medicine, University of Michigan Medical School, Ann Arbor, \\ Michigan, USA
}

\begin{abstract}
We evaluated suspected hepatic lesions in 30 patients using both nongated spin-echo magnetic resonance imaging (MRI) on a $0.35 \mathrm{~T}$ superconducting magnet and contrast-enhanced dynamic incremental computed tomography (CT). In the 27 patients with focal lesions, both modalities detected abnormalities in 26 patients. Liver lesions were equally well demonstrated using MRI and CT in 15 patients, better demonstrated by $\mathrm{CT}$ in 11 patients, and better demonstrated by MRI in 1 patient. Small lesions $(<2 \mathrm{~cm})$ were much better demonstrated using CT than MRI; this was significant when knowledge of the precise extent of disease was necessary for planning surgical therapy or for evaluating response to chemotherapy. Five patients had significant extrahepatic disease detected by CT; MRI identified extrahepatic abnormalities in only 2 of these 5 patients. We conclude that at the current time CT is more useful than nongated spin-echo MRI in the evaluation of suspected hepatic masses.
\end{abstract}

Key words: Liver, magnetic resonance imaging Liver, computed tomography - Liver, neoplasms.

Magnetic resonance imaging (MRI) of the liver has already demonstrated considerable promise in the evaluation of suspected lesions [1-7]. However, very few studies available compare MRI with existing modalities using state-of-the-art equipment and technique. In this investigation we evaluated suspected hepatic lesions using both spin-echo MRI on a $0.35 \mathrm{~T}$ superconducting magnet and

Address reprint requests to: Gary M. Glazer, M.D., Department of Radiology - Box 13, University of Michigan Medical School, Ann Arbor, MI 48109, USA contrast-enhanced dynamic incremental computed tomography (CT) [8,9]. The results of this study form the basis of our report.

\section{Materials and Methods}

Thirty patients with known or suspected liver masses were studied using both MRI and CT. The initial 9 were selected on the basis of a positive CT scan. The next 21 patients were prospectively examined by both techniques after being referred from the oncology service. In 17 of these patients, liver metastases were already pathologically proven and the exams were performed to evaluate tumor response to hepatic arterial chemotherapy.

Magnetic resonance imaging was performed on a $0.35 \mathrm{~T}$ superconducting magnet (Diasonics Inc.) using nongated spinecho imaging; details of the imager have been described previously [10]. Multiple spin-echo pulse sequences (TR 0.5 or $1.0 \mathrm{sec}$ and either $1.5 \mathrm{or} 2.0 \mathrm{sec}$, TE 28 and $56 \mathrm{msec}$ ) were obtained in all patients. Other TR or TE intervals are not selectable on this instrument. Respiratory gating was not used because of technical difficulties in its routine implementation. Also, oral paramagnetic contrast was not used in this study. $\mathrm{T} 1$ and $\mathrm{T} 2$ relaxation times were calculated from the intensity data [11] in the first 10 patients; they were not calculated in the 20 other patients because of difficulties in reliable quantification as previously reported $[4,5]$.

All CT scans were performed on 3rd generation scanners (General Electric CT/T 8800 or 9800) using the contrast-enhanced dynamic incremental technique; $100 \mathrm{ml}$ meglumine iothalamate $60 \%$ (Conray ${ }^{\ominus} 60$ ) was hand-injected as an intravenous bolus immediately before scanning $[8,9]$. Dilute oral contrast was administered before scanning to all patients. Scans were photographed at both soft tissue (width 500 , level $30 \mathrm{HU}$ ) and liver (width 150 , level $70 \mathrm{HU}$ ) windows prior to interpretation.

Both MRI and CT scans were independently reviewed at the time of the initial examination by the authors and dictated for the clinical record. All scans were evaluated retrospectively by the senior author. The scan data were then grouped into 3 categories: Group I, MRI and CT equal in hepatic evaluation; Group II, MRI better than CT; Group III, CT better than MRI. To minimize subjective bias, a modality was considered "better" than the other only when it detected disease occult to the other modality, when numerous additional lesions were identified, or when extent of disease was much more 
clearly defined. Evaluation of the extrahepatic upper abdomen was also performed using similar categories.

\section{Results}

Of the 30 patients studied, 27 had focal liver abnormalities; final diagnoses are listed in Table 1. Twenty-three patients (metastases in 17, hepatomas 2 , abscesses 3 , regenerating nodule 1 ) had tissue proof of the final diagnosis, while in 7 patients the diagnosis was proven clinically. In 3 of these 7 patients the liver was considered normal on the basis of normal MRI and CT scans as well as clinical follow-up. In 1 patient with tissue-proved endstage cirrhosis (without evidence for hepatoma), the visualized lesions (seen only on MRI) were assumed to represent regenerating nodules. One patient with a large $(9 \mathrm{~cm})$ focal mass, assumed to be a primary liver tumor on the basis of MRI, $\mathrm{CT}$, and angiographic evaluation, declined surgery or biopsy. In another patient, a diagnosis of hepatic infarction was established on the basis of angiography and compatible clinical findings. Final-

Table 1. Final hepatic diagnosis

\begin{tabular}{lc}
\hline Diagnosis & Number \\
\hline Metastases & $17^{\mathrm{a}}$ \\
Primary liver tumor & 3 \\
Abscess & 3 \\
Normal & 3 \\
Regenerating nodules & 2 \\
Infarction & 1 \\
Cyst & 1 \\
\hline
\end{tabular}

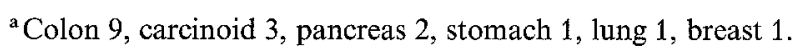

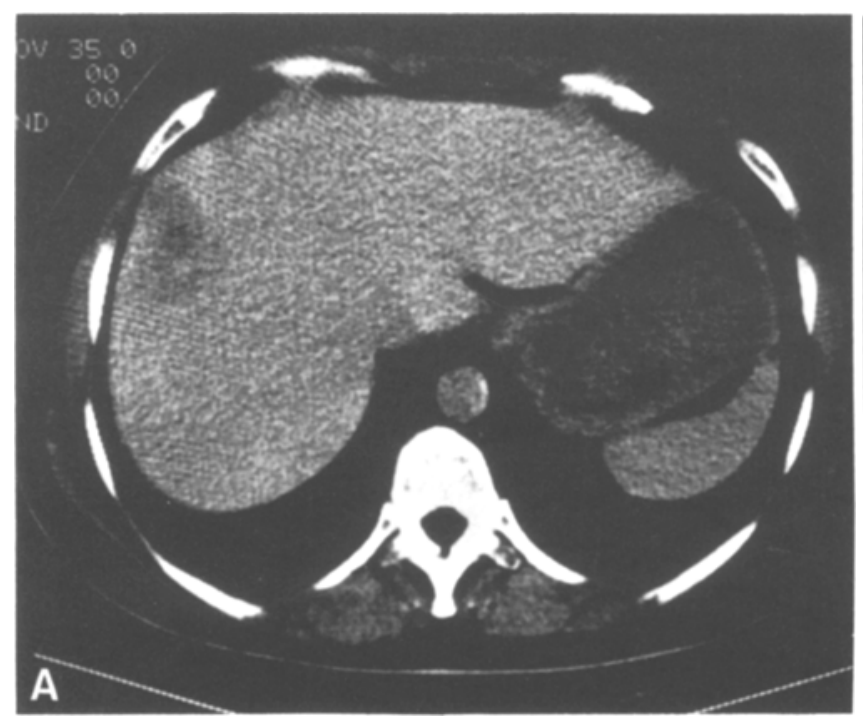

ly, 1 patient had no tissue proof of liver status because CT demonstrated a classic hepatic cyst. Of the 27 patients with focal lesions, initial scan interpretation of both modalities detected at least 1 mass in 21 patients, whereas in 5 patients lesions were not detected by MRI ( 3 metastases, 1 infarct, 1 regenerating nodule), and in 1 patient (the other patient with regenerating nodule) $\mathrm{CT}$ failed to identify a hepatic abnormality. When scans were retrospectively reviewed, both modalities detected at least 1 lesion in 26 patients, with MRI and CT each failing to identify a regenerating nodule in different patients. When MRI and CT scans were assigned to 1 of 3 groups as described, both modalities were equivalent in 15 patients (Fig. 1), CT was more informative in 11 patients (Figs. 2-4), and MRI was better in 1 patient (Fig. 5).

The extrahepatic upper abdomen was normal in 25 patients and abnormal in 5 others. Magnetic resonance detected extrahepatic disease in 2 patients (adrenal mass in 1 patient; adrenal mass, retroperitoneal adenopathy, and pulmonary nodules in another patient) whereas CT detected extrahepatic abnormalities in 5 patients (identical findings to MRI in the 2 patients, plus gastric thickening due to carcinoma in 1 patient, splenic metastases in another patient, and anastomotic site colon carcinoma recurrence in a final patient) (Fig. 6).

The relative intensities of the liver lesions compared to normal hepatic parenchyma for the various spin-echo MRI pulse sequences are presented in Table 2. As previously noted, many lesions were isointense at any 1 pulse sequence [4]; however, at the TR 1.5 or $2.0 \mathrm{sec}$, TE 28 and $56 \mathrm{msec} \mathrm{se}-$ quences only 1 lesion (regenerating nodule) was

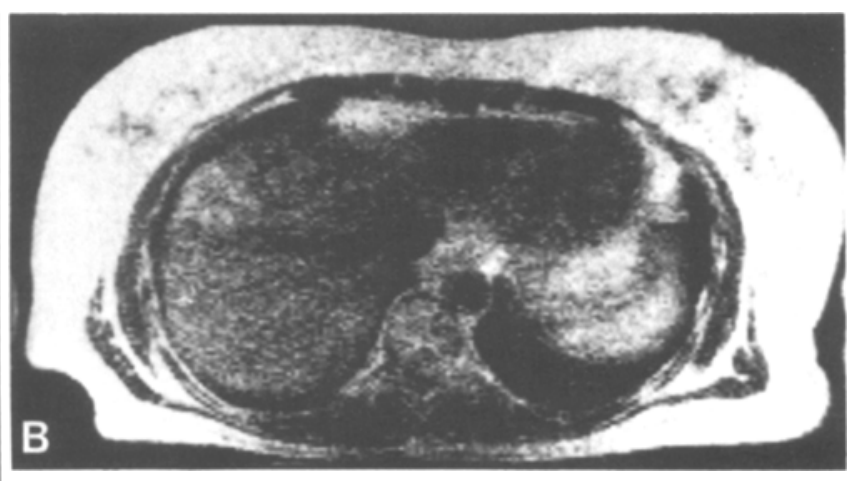

Fig. 1. Findings on CT and MRI studies of metastatic colon carcinoma. A Solitary hepatic metastasis evident on postcontrast CT. B Magnetic resonance imaging (TR $2.0 \mathrm{sec}$, TE $56 \mathrm{msec}$ ) demonstrates the metastasis as well as CT. 

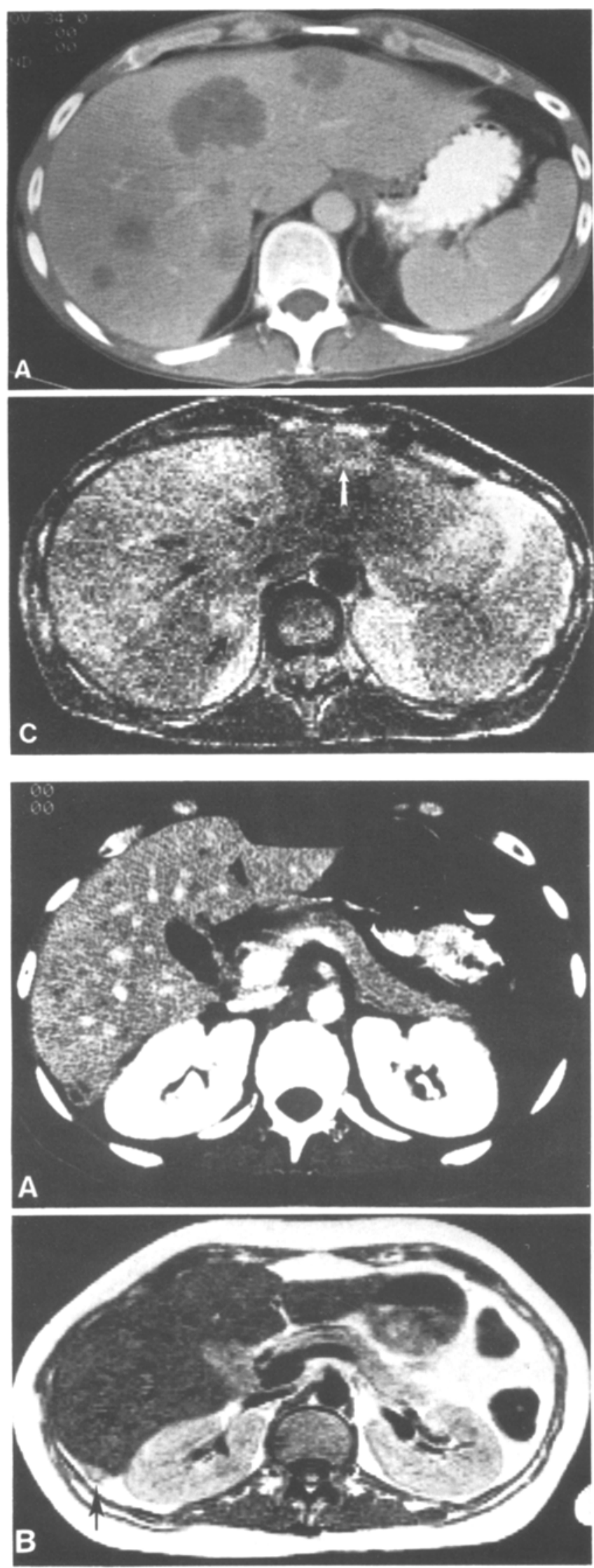

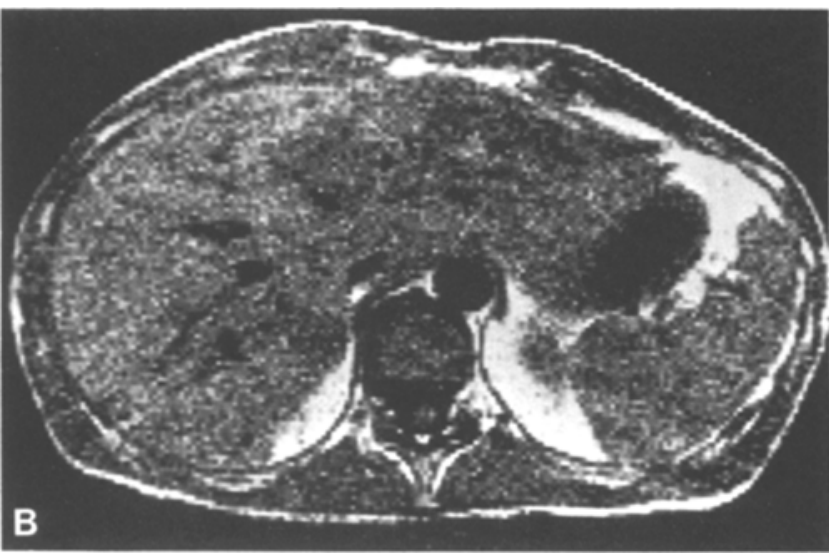

Fig. 2. Metastatic colon carcinoma. Extent of disease is better defined on CT. A Postcontrast CT at plane of celiac axis shows innumerable focal metastases. B At same plane MRI (TR $2.0 \mathrm{sec}$, TE $28 \mathrm{msec}$ ) demonstrates hyperintense lesions with less clarity. C At TR $2.0 \mathrm{sec}$, TE $56 \mathrm{msec}$ (lesions even less well defined at TR $0.5 \mathrm{sec}$ ). Arrow indicates metastasis in lateral segment; left lobe poorly depicted on MRI.

Fig. 3. Candida hepatic microabscesses in leukemic patient; CT better defines the number of lesions. A Multiple tiny, lowattenuation hepatic lesions on CT. B Several lesions barely visible at TR $1.0 \mathrm{sec}$, TE $28 \mathrm{msec}$. Note lesion at posterior tip of right lobe (arrow). C On TR $1.0 \mathrm{sec}$, TE $56 \mathrm{msec}$ image, fewer lesions are visible than on CT and are difficult to distinguish from hepatic vein branches.

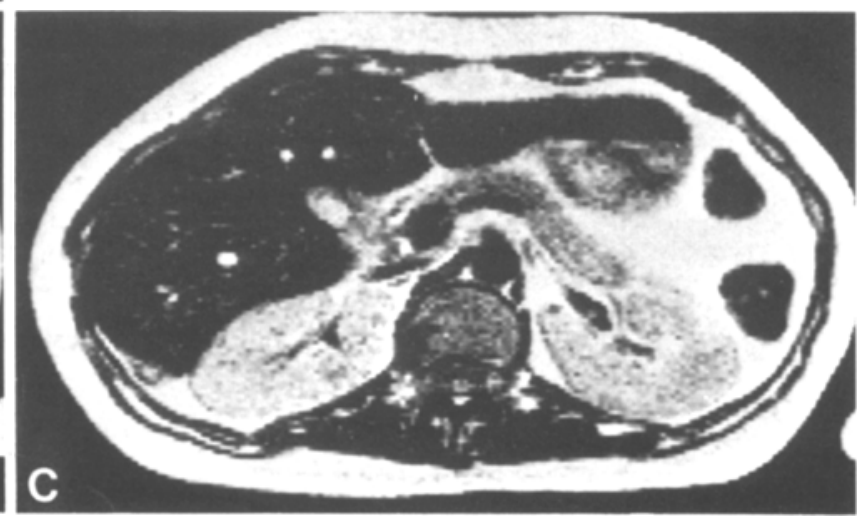



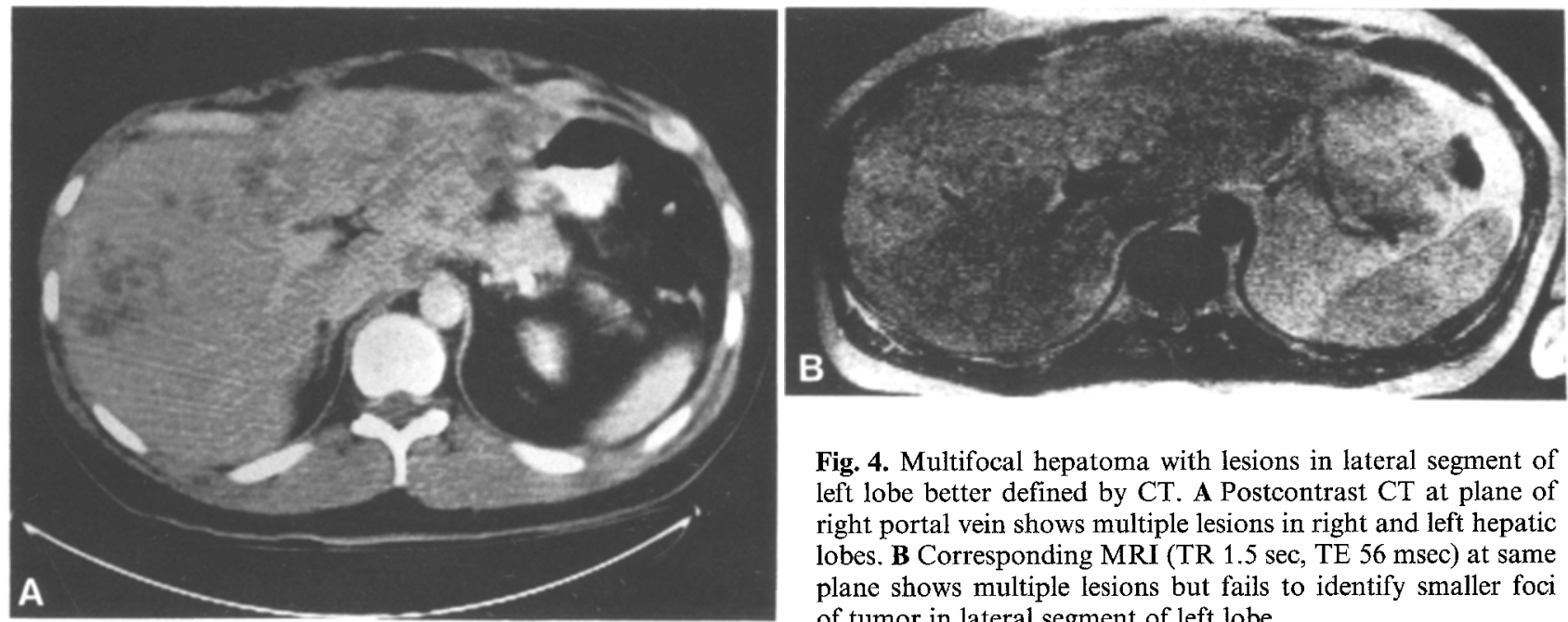

Fig. 4. Multifocal hepatoma with lesions in lateral segment of left lobe better defined by CT. A Postcontrast CT at plane of right portal vein shows multiple lesions in right and left hepatic lobes. B Corresponding MRI (TR $1.5 \mathrm{sec}$, TE $56 \mathrm{msec}$ ) at same plane shows multiple lesions but fails to identify smaller foci of tumor in lateral segment of left lobe.
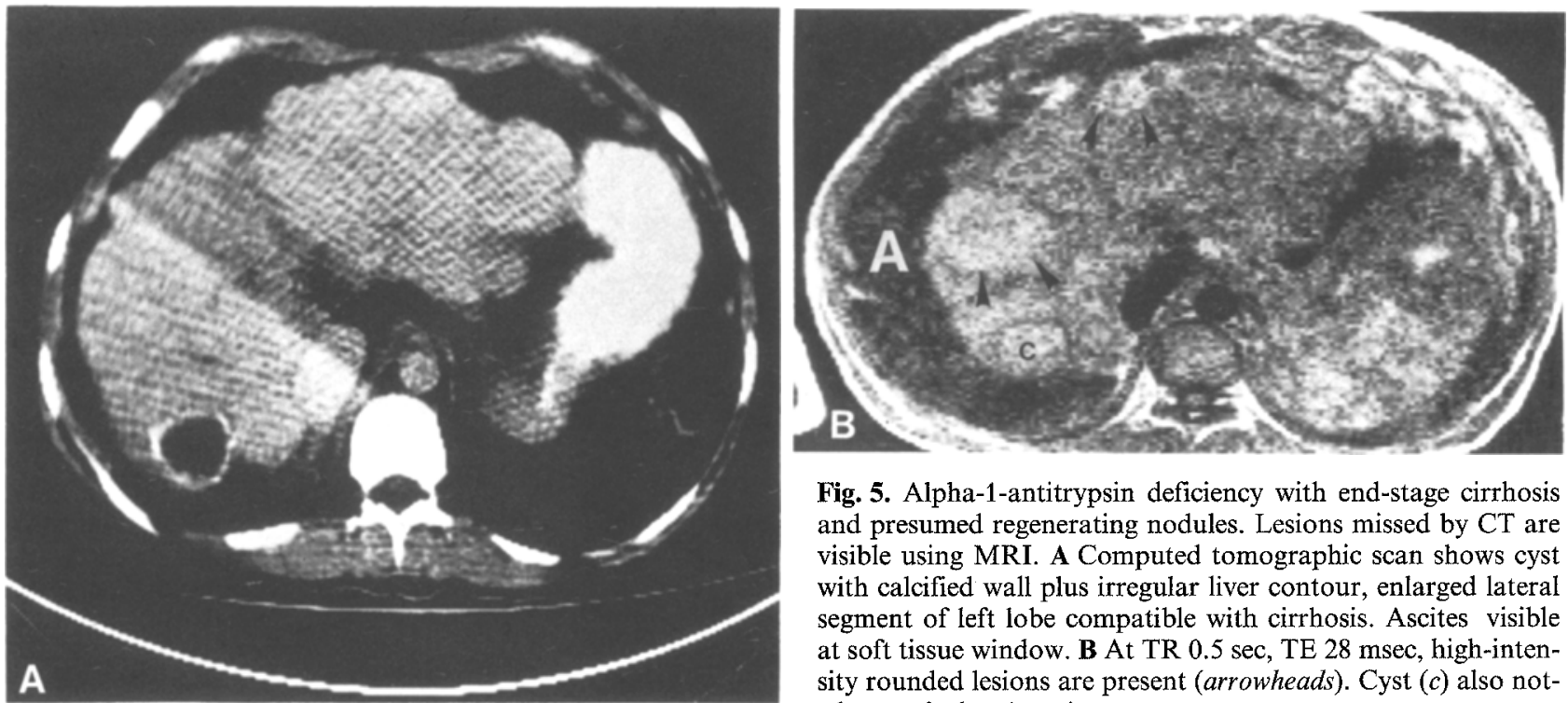

Fig. 5. Alpha-1-antitrypsin deficiency with end-stage cirrhosis and presumed regenerating nodules. Lesions missed by CT are visible using MRI. A Computed tomographic scan shows cyst with calcified wall plus irregular liver contour, enlarged lateral segment of left lobe compatible with cirrhosis. Ascites visible at soft tissue window. B At TR $0.5 \mathrm{sec}$, TE $28 \mathrm{msec}$, high-intensity rounded lesions are present (arrowheads). Cyst (c) also noted posteriorly. $A$, ascites.
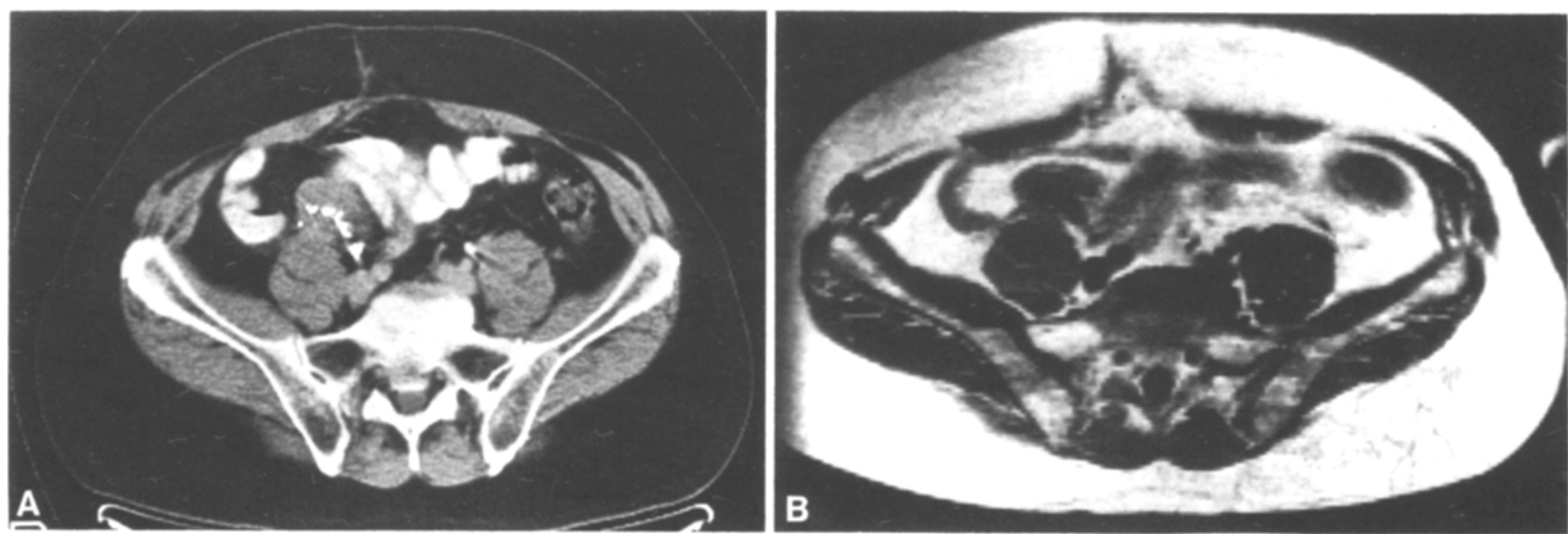

Fig. 6. Recurrence of colon carcinoma at site of anastomosis. A Computed tomographic scan clearly shows soft tissue mass displacing opacified bowel from surgical clips. B Mass cannot be distinguished from normal bowel on corresponding MRI. 

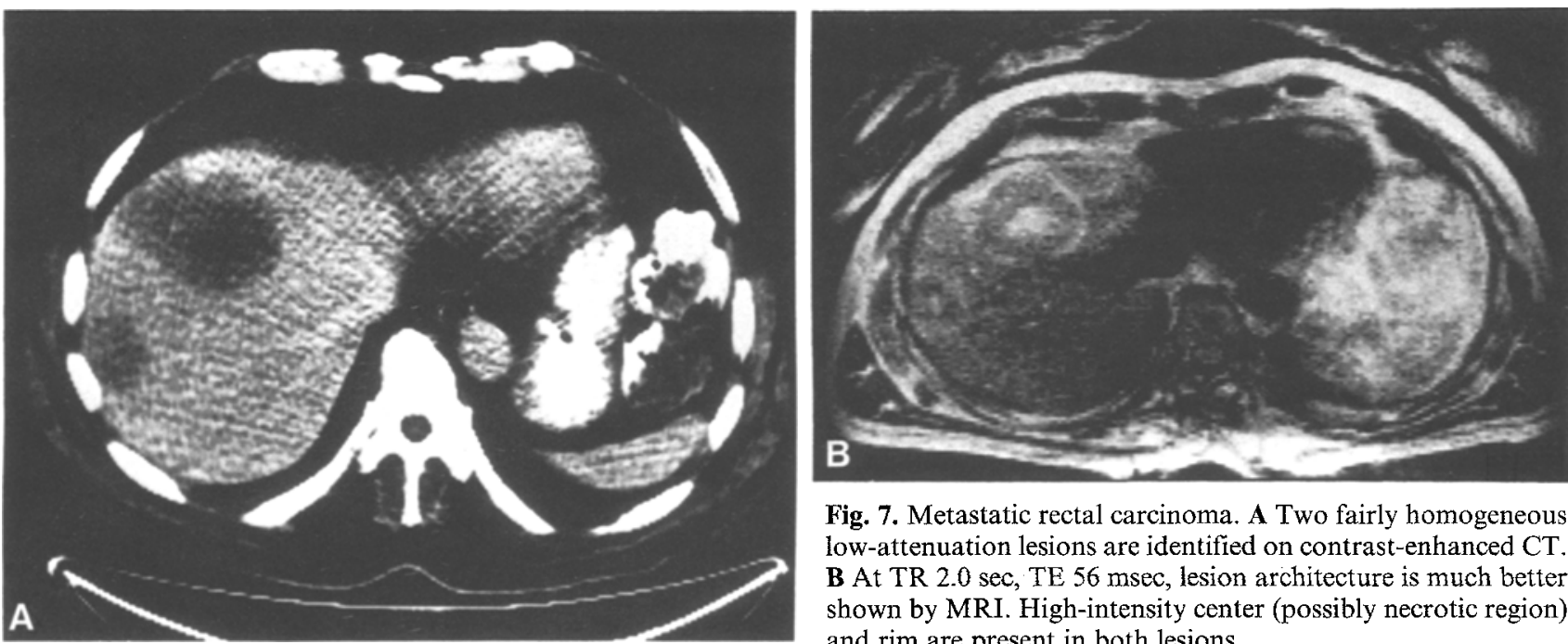

Fig. 7. Metastatic rectal carcinoma. A Two fairly homogeneous low-attenuation lesions are identified on contrast-enhanced CT. B At TR $2.0 \mathrm{sec}$, TE $56 \mathrm{msec}$, lesion architecture is much better shown by MRI. High-intensity center (possibly necrotic region) and rim are present in both lesions.

Table 2. MRI appearance of liver lesions in 27 patients

\begin{tabular}{lcccc}
\hline $\begin{array}{l}\text { Lesion intensity relative } \\
\text { to normal liver }\end{array}$ & TR $0.5 \mathrm{sec}$ & TR $0.5 \mathrm{sec}$ & TR 1.5 or 2.0 sec & $\begin{array}{c}\text { TR 1.5 or 2.0 sec } \\
\text { TE 56 msec }\end{array}$ \\
\hline Diminished & TE 28 msec & TE 56 msec & TE 28 msec & 2 \\
Isointense & 12 & 8 & 4 & 6 \\
Increased & 14 & 15 & 7 & 19 \\
\hline
\end{tabular}

isointense, whereas in 8 patients lesions were not detectable when a TR interval of $0.5 \mathrm{sec}$ was used (3 patients with metastases, 2 hepatomas, 1 infarct, 1 abscess, 1 regenerating nodule). No lesion was seen solely at TR $0.5 \mathrm{sec}$; however, internal architecture and lesion extent were sometimes best defined at this pulse sequence. At a short TR interval $(0.5 \mathrm{sec})$, lesions tended to be either hypointense or isointense, whereas the lesions were generally hyperintense at long TR intervals $(1.5$ or $2.0 \mathrm{sec})$. In some lesions equally well detected by both modalities, internal architecture was significantly better defined with MRI than CT (Fig. 7).

The calculated $\mathrm{T} 1$ and $\mathrm{T} 2$ relaxation times (10 patients) were 378 (SD 164, range 295$811 \mathrm{msec}$ ) and 50 (SD 17, range $37-100 \mathrm{msec}$ ), respectively, in normal liver and 684 (SD 242, range 238- $1100 \mathrm{msec}$ ) and 66 (SD 15, range 39-89 $\mathrm{msec}$ ) in the liver lesions.

\section{Discussion}

Prior investigations have reported that MRI and CT are roughly comparable in detecting focal hepatic lesions $[1,2,4]$. These studies were relatively uncritical since only the presence or absence of disease was evaluated. Since hepatic lesions are of- ten large and multiple, differences between modalities are unlikely to be reflected solely by their ability to detect disease. When we analyzed our data more critically, we found nongated spin-echo MRI using the commercially available pulse sequences noted inferior to contrast-enhanced dynamic CT in the evaluation of liver lesions. In this study, CT more clearly defined the hepatic lesions in $11 / 27(41 \%)$ patients. Furthermore, in $3 / 5$ patients with significant extrahepatic disease, MRI missed abnormalities detectable using CT.

Clear definition of the extent of hepatic disease is important in 2 major instances. First, in patients with disease that may be treatable surgically (abscess, hepatoma, or other primary tumors sparing at least 1 hepatic segment) the precise distribution of disease is of major importance and influences surgical management. Magnetic resonance imaging would have been misleading in planning surgical therapy in 3 of our patients; in 1 patient hepatoma involved all liver segments on CT examination but apparently spared the lateral segment of the left lobe on MRI. In 2 other patients the number of hepatic abscesses was underestimated using MRI. Secondly, in patients undergoing medical treatment such as hepatic arterial chemotherapy for liver metastases, the precise extent of disease is im- 
portant to establish so that effects of therapy can be monitored. Thus, although MRI and CT both detected presence or absence of hepatic disease with comparable accuracy in our series, the ability of CT to define more accurately the extent of disease made it much more clinically efficacious. Many of the masses identified using CT but missed by MRI were small, measuring less than $2 \mathrm{~cm}$. It seems likely that image blurring from respiratory motion significantly affected the ability to detect these small lesions [12]. Respiratory gating was not available to us at the time of this study; however, when implemented, it will likely improve lesion detection at the expense of significantly increased MRI imaging time.

In our study we only used spin-echo imaging; the average time of MRI examination was $1-1^{1 / 2}$ hours. Because of time constraints, we were unable to use inversion-recovery sequences. This may have significantly biased our results. However, a recent investigation using identical MRI equipment reported equivalent hepatic lesion detectability using inversion-recovery pulse sequences and the same spin-echo pulse sequences we used [4]. Another limitation to this study was the inability, due to equipment constraints, to obtain images at either very short TR or long TE intervals; the effect of this limitation on lesion detectability is unclear. Another significant limitation relates to the fact that we examined our patients on only 1 commercially available MRI imager; thus our results may not accurately reflect the capabilities of MRI using different equipment.

Although our results are somewhat pessimistic regarding the current clinical value of nongated spin-echo MRI using the pulse sequences reported in evaluating hepatic masses, they should be placed in proper perspective. Magnetic resonance imaging is relatively new and significant improvements in the technology are occurring rapidly. More specifically, further refinements in equipment that improve signal-to-noise ratio, the development of combined cardiac and respiratory gating, additional pulse sequences (e.g., chemical shift imaging) [13], and intravenous (as well as oral) contrast agents [14] can be expected to improve significantly the accuracy of the method.

Quantitation of the relaxation parameters, which is currently not useful, may also prove more valuable in the future when these measurements are less affected by biological motion and equipment artifacts [12]. The internal architecture of a lesion is often better depicted by MRI than CT, which raises the possibility of differentiating viable from necrotic tissue within a lesion. Finally, this study included a heterogeneous group of hepatic lesions and it is probable that at least a subset of such lesions will be equally or better defined using MRI than by CT (e.g., hemangiomas) [15].

\section{References}

1. Borkowski GP, Buonocore E, George CR, Go RT, O'Donovan PB, Meaney TF: Nuclear magnetic resonance (NMR) imaging in the evaluation of the liver: a preliminary experience. $J$ Comput Assist Tomogr 7:768-774, 1983

2. Doyle FH, Pennock JM, Banks LM, McDonnell MJ, Bydder GM, Steiner RE, Young IR, Clarke GJ, Pasmore T, Gilderdale DJ: Nuclear magnetic resonance imaging of the liver: initial experience. $A J R$ 138:193-200, 1982

3. Smith FW, Mallard JR, Reid A, Hutchison JMS: Nuclear magnetic resonance tomographic imaging in liver disease. Lancet 1:963-966, 1982

4. Moss AA, Goldberg HI, Stark DB, Davis PL, Margulis AR, Kaufman L, Crooks LE: Hepatic tumors: magnetic resonance and CT appearance. Radiology 150:141-147, 1984

5. Stark DD, Bass NM, Moss AA, Bacon BR, McKerrow JH, Cann CE, Brito A, Goldberg HI: Nuclear magnetic resonance imaging of experimentally induced liver disease. Radiology 148:743-751, 1983

6. Stark DD, Goldberg HI, Moss AA, Bass NM: Chronic liver disease: evaluation by magnetic resonance. Radiology $150: 149-151,1984$

7. Margulis AR, Moss AA, Crooks LE, Kaufman L: Nuclear magnetic resonance in the diagnosis of tumors of the liver. Semin Roentgenol 18:123-126, 1983

8. Glazer GM, Francis IR, Gebarski KS, Samuels BI, Sorenson $\mathrm{KW}$ : Contrast-enhanced dynamic incremental $\mathrm{CT}$ in the evaluation of the pulmonary hila. $J$ Comput Assist Tomogr 7:57-64, 1983

9. Foley WD, Berland LL, Lawson TL, Smith DF, Thorsen MK: Contrast enhancement technique for dynamic hepatic computed tomographic scanning. Radiology 147: 797-803, 1983

10. Crooks L, Arakawa M, Hoenninger J, Watts S, McRee R, Kaufman L, Davis PL, Margulis AR, DeGroot J: Nuclear magnetic resonance whole-body imager operating at 3.5 KGauss. Radiology 143:169-174, 1982

11. Herfkens R, Davis P, Crooks L, Kaufman L, Price D, Miller $\mathrm{T}$, Margulis A, Watts J, Hoenninger J, Arakawa M, McRee $R$ : Nuclear magnetic resonance imaging of the abnormal live rat and correlations with tissue characteristics. Radiology 141:211-218, 1981

12. Schultz CL, Alfidi RJ, Nelson AD, Kopiwoda SY, Clampitt ME: The effect of motion on two-dimensional Fourier transformation magnetic resonance images. Radiology 152:117-121, 1984

13. Dixon WT, Faul DD: Simple proton spectroscopic imaging. Radiology 153:189-194, 1984

14. Carr DH, Brown J, Bydder GM, Steiner RE, Weinmann HJ, Speck U, Hall AS, Young IR: Gadolinium-DTPA as a contrast agent in MRI : initial clinical experience in 20 patients. AJR 143:215-224, 1984

15. Glazer GM, Aisen AM, Francis IR, Gyves JW, Lande I, Adler $\mathrm{DD}$ : Magnetic resonance imaging of hepatic cavernous hemangioma. Radiology $155: 417-420,1985$

Received: August 16, 1985; accepted: October 23, 1985 